\title{
3D Geological Modelling of the Renard 2 Pipe, Québec, Canada: From Exploration to Extraction
}

\author{
I. Lepine ${ }^{1}$ and D.J. Farrow ${ }^{2}$ \\ 1Stornoway Diamond Corporation, North Vancouver, Canada, ilepine@stornowaydiamonds.com \\ 2 GeoStrat Consulting Services Inc., North Vancouver, Canada, darrell.farrow@geotrat.ca
}

\section{Introduction}

The Renard 2 pipe is one of nine diamondiferous pipes situated in the Renard kimberlite cluster in northern Québec, Canada and is the main body presently being extracted at the Renard Diamond Mine. Located in the south-eastern portion of the Superior Province, the Renard 2 pipe was emplaced $\sim 640 \mathrm{Ma}$ (Fitzgerald et al., 2009) into Archean gneiss and granitic rocks.

Renard 2 has been the subject of numerous diamond drilling campaigns since its discovery in 2001 . The first three dimensional (3D) model of this pipe was completed in 2006. A change in modeling philosophy and subsequent targeted drilling in 2009 resulted in a significant increase to the pipe size, depth and contained mineral resource (Muntener and Scott Smith, 2013). The new 2009 3D model was updated in 2015 following a program of deep directional drilling.

\section{Geology}

The Renard 2 kimberlite pipe consists of two main pipe infills, Kimb2a and Kimb2b which are classified as Kimberley-type pyroclastic kimberlite (KPK). A marginal country rock breccia (CRB) interpreted as part of the kimberlite emplacement event surrounds the kimberlititc units. Extensive intrusive coherent kimberlite (Kimb2c) occurs as late stage, cross cutting dykes and irregular intrusions within Kimb2a, Kimb2b and CRB. Renard 2 is interpreted as a diatreme-zone kimberlite with local irregularities in the upper portion but an overall smooth and tapering shape when the emplacement envelope is considered. It is slightly elongated on its north-south axis and has a subcircular surface expression of 2.3 hectares.

\section{D Modelling}

The first 3D model completed in 2006 consisted of only the kimberlitic units modelled as one shape. The second model completed in 2008 comprised three geological domains, Kimb2a, Kimb2b and CRB, modelled separately (Figures $1-3$ ) to a depth of $540 \mathrm{~m}$. Two separate unconnected areas of coherent kimberlite were modelled, but their genesis was not understood at the time.

In 2009 a new approach to 3D modeling was adopted whereby the entire kimberlite pipe event was modelled and then divided into five main geological domains: Kimb2a, Kimb2b, CRB, CRB2a and CCR (Figures 1 - 3). Due to the spatial distribution of the Kimb2c, it was not possible to model these numerous drill intersections and consequently the Kimb2c was included within each geological domain. Where Kimb2c is in contact between two geological units, it was modelled with the more coherent kimberlitic unit, i.e., if a Kimb2c intersection was in contact with Kimb2b and Kimb2a, it was modeled in the Kimb2b domain.

This new approach of modelling the entire kimberlite, including the emplacement envelope and projecting the modelled pipe shape to depth, allowed more focused targeting of deep drilling where kimberlite had not yet been discovered. This targeted drilling resulted in an increase in the Indicated Resource of 5.3 million $\mathrm{m}^{3}$.

In 2015, the 2009 model was updated following a program of deep directional drilling and extended the base of the pipe shape from $710 \mathrm{~m}$ to a depth of $865 \mathrm{~m}$ below surface (Figures 1 - 3). The total 
volume of the Indicated Resource was estimated at 12.3 million $\mathrm{m}^{3}$, an increase of 5.6 million $\mathrm{m}^{3}$ (Farrow and Hopkins, 2015).

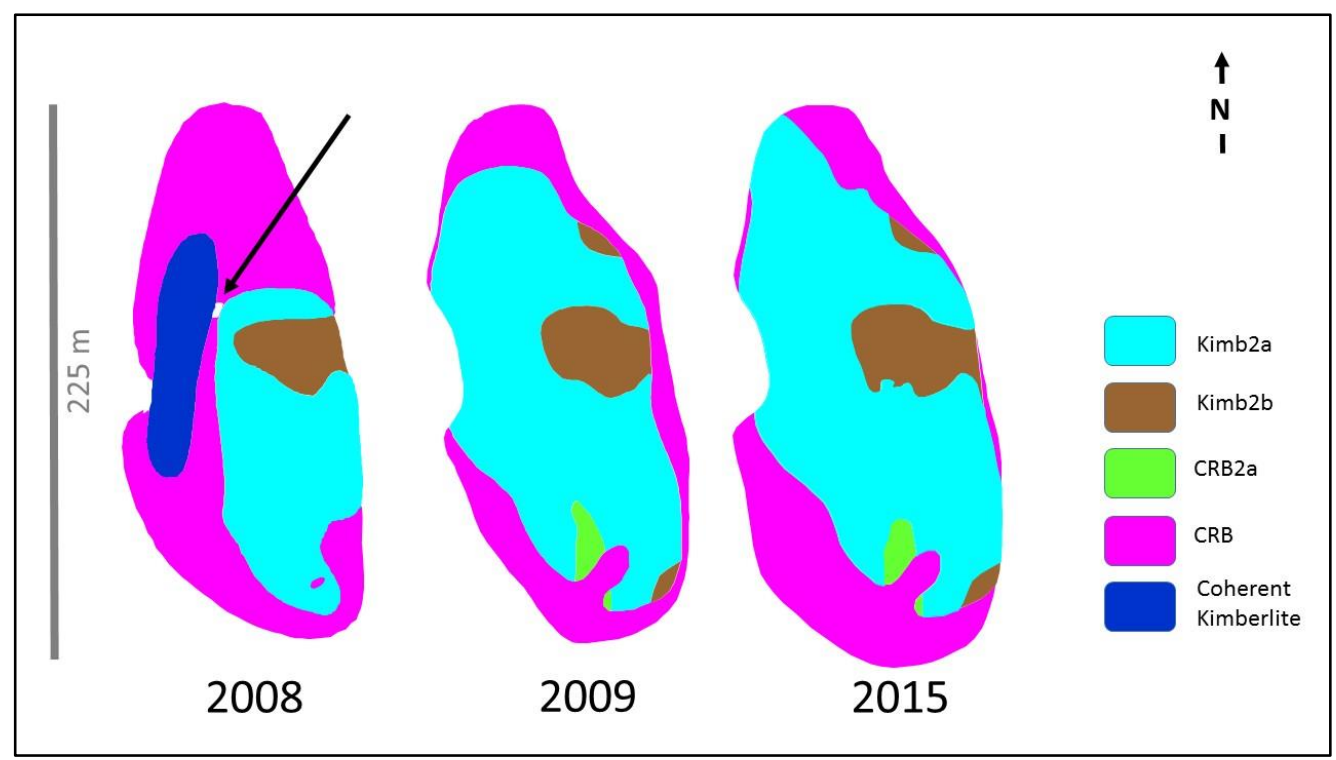

Figure 1: Plan view at $308 \mathrm{~m}$ above sea level (a.s.1.) comparing the 2008, 2009 and 2015 geological models. Note the gap in the 2008 model between the coherent kimberlite and the Kimb2a domain created by individually modeling each domain (arrow).

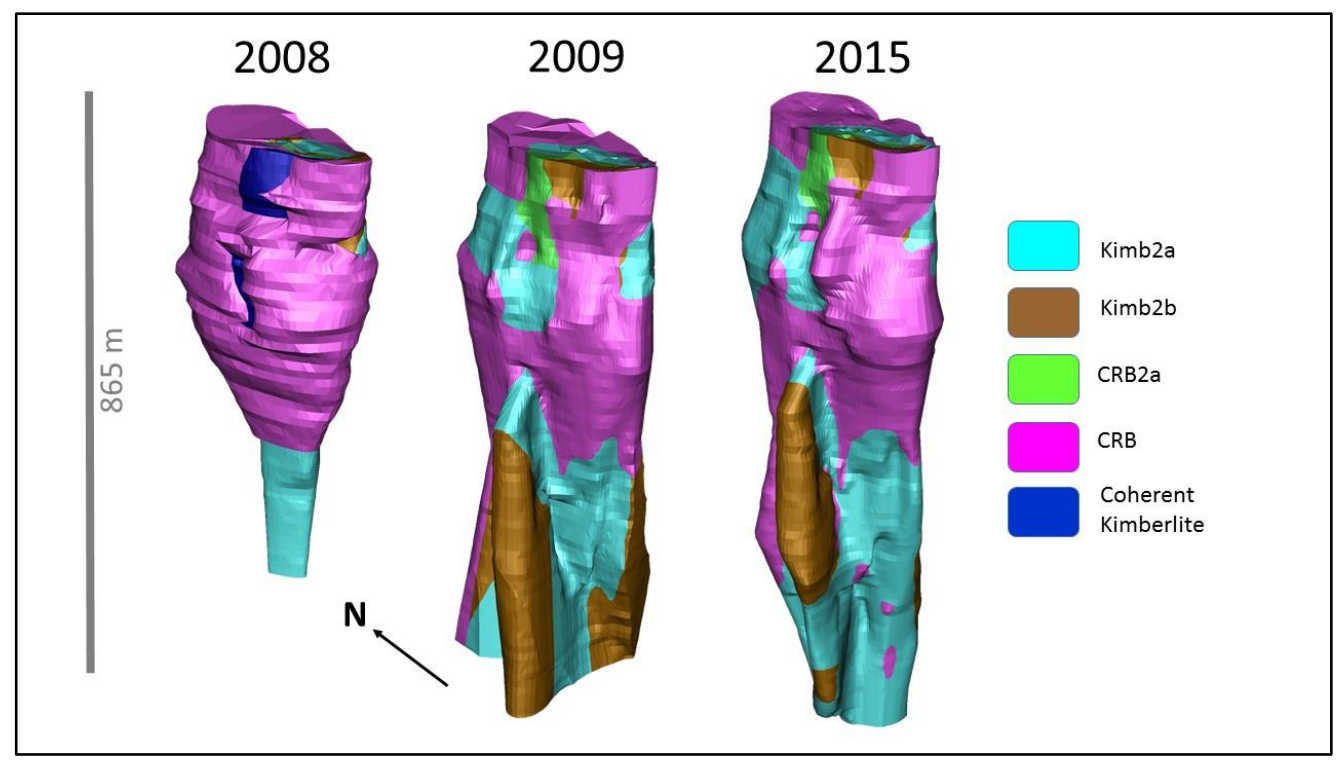

Figure 2: Comparison of 2008, 2009 and 2015 Renard 2 3D geological models (depth of 575 m, 710 and 865 m from surface, respectively). The emplacement envelope (CCR) is not shown for clarity.

\section{Modelling and Drilling Density}

The initial modeling approach used only the main kimberlite units and led to a large amount of drilling in the upper portion of the pipe in order to determine the geology and morphology of the kimberlite. The new approach, adopted in 2009, used a series of holes drilled horizontally from the underground exploration sampling level to constrain the shape of the pipe on this level. This shape was successively adjusted to accommodate contacts in drill holes at other depths. Modeling in this way highlighted that the upper portion of the pipe did not change in shape much, and had therefore been over drilled. 
For the basic definition of the kimberlite pipe shape, the best drilling approach is to generate a series of pierce points at regularly spaced intervals, rather than on section as is a customary approach in exploration drilling. Defining the pipe shape on one level and using this to guide the modeling, requires significantly less drilling. Removal of a significant proportion of holes drilled on Renard 2 would have resulted in the same pipe shape.

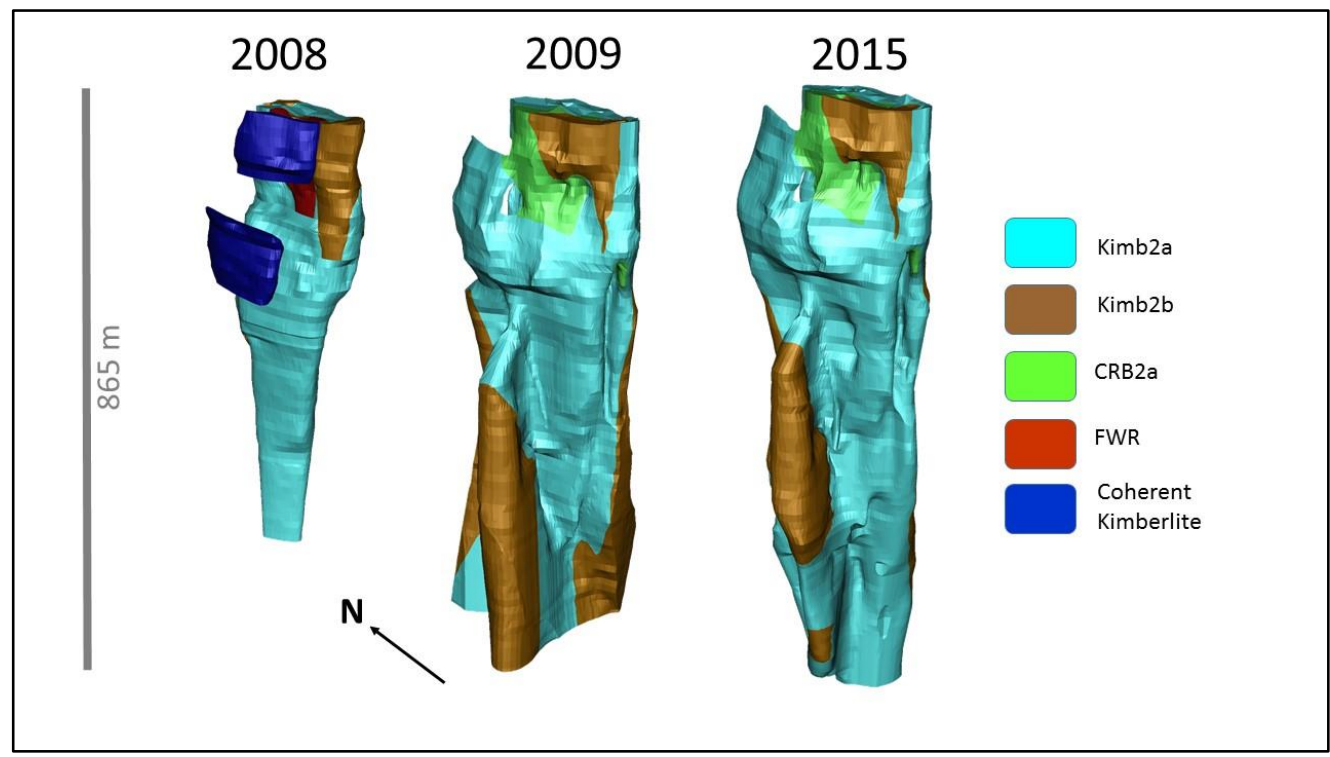

Figure 3: Comparison of 2008, 2009 and 2015 Renard 2 3D geological models excluding the CRB. Note the individually modeled coherent kimberlite units in the 2008 model. In the 2008 model, FWR stands for further work required.

\section{Mining}

The Renard 2 pipe is presently the focus of open pit mining and at the end of 2016 , five $10 \mathrm{~m}$ benches had been completed in the open pit. Underground development has commenced on the $160 \mathrm{~m}$ mining depth level (or $355 \mathrm{~m}$ a.s.l). The open pit and underground mapping of the pipe shape corresponds well to the 2015 3D model and no major contact changes have as of yet been observed. Country rock/kimberlite contacts have been encountered within $1 \mathrm{~m}$ of the modeled contacts. Open pit mining has revealed a large Kimb2c dyke in the CRB domain which was not possible to model from drilling intersections.

\section{Conclusions}

Modeling individual kimberlite units separately resulted in a significant underestimation of the kimberlite body and over drilling of the upper portion of the pipe. A systematic approach, consisting of modeling the entire kimberlite emplacement event allows for more focused targeting of delineation drilling and minimises the number of drill holes required to obtain a robust 3D geological model that can be used for resource modeling and feasibility studies.

\section{References}

Fitzgerald CE, Hetman CM, Lépine I, Skelton DS, McCandless TE (2009) The internal geology and emplacement history of the Renard 2 kimberlite, Superior Province, Quebec, Canada. Lithos 112S, pp 513-528

Muntener C and Scott Smith BH (2013) Economic Geology of Renard 3, Québec, Canada: A Diamondiferous, Multi-Phase Pipe Infilled with Hypabyssal and Tuffisitic Kimberlite. Proceedings of the $10^{\text {th }}$ International Kimberlite Conference, Springer India, Vol 2, pp 241-256 